PACS: 47.10.ad, 47.11.-j, 47.20.Bp, 47.20.Qr, 47.27.Te, 47.32.-y, 47.55.pb

\title{
THE STABILITY OF A ROTATING AND HEATED FROM BELOW HORIZONTAL CYLINDRICAL LAYER OF A VISCOUS, INCOMPRESSIBLE LIQUID WITH FREE BOUNDARIES
}

\author{
Doksana L. Andreeva ${ }^{1,2 *}$, (D) Leonid A. Bulavin'3, (DViktor I. Tkachenko ${ }^{1,2}$ \\ ${ }^{I}$ National Science Center Kharkiv Institute of Physics and Technology \\ 1, Academichna Str., 61108 Kharkiv, Ukraine \\ ${ }^{2}$ V.N. Karazin Kharkiv National University \\ 4, Svobody Sq., 61022 Kharkiv, Ukraine \\ ${ }^{3}$ Taras Shevchenko National University of Kyiv \\ 64/13, Volodymyrska Street, 01601 Kyiv, Ukraine \\ *E-mail: andreeva@kipt.kharkov.ua \\ Received September 12, 2019; revised October 28, 2019; accepted November 15, 2019
}

\begin{abstract}
The stability of a rotating and heated from below horizontal cylindrical layer of a viscous, incompressible liquid with free boundaries was theoretically investigated. Neglecting the centrifugal forces, the equations of motion, thermal conductivity and incompressibility of the liquid were written, from which the well-known dispersion equation was derived in the linear approximation. The stability of a rotating cylindrical volume of a liquid with no heating from below was considered, provided that the temperature difference between the horizontal boundaries of the liquid was fixed and equal to zero. It was demonstrated, that with no heating from below the temperature difference between the horizontal boundaries of the rotating liquid was not fixed and not maintained from the outside, the perturbed liquid temperature would increase, but its final value did not exceed the phase transition temperature. The obtained result was used to explain the heating of water in Ranque - Hilsch vortex tubes. It was concluded that the water heating in Ranque Hilsch tubes should be considered as the inverse Rayleigh problem, in which the temperature gradient can be determined from the known distribution of velocities inside the volume. The stability of a rotating cylindrical volume of a liquid when heated from below was analyzed. It was demonstrated, that the value of the specified temperature difference at cylinder boundaries, as well as the initial rate of its variation, determine the final heating temperature of the liquid. A comparison of the proposed theory and experimental data for water heating shows their good qualitative and quantitative agreement.
\end{abstract}

KEY WORDS: theory, stability, viscous, incompressible, liquid, horizontal cylindrical layer, rotating, heated, free boundaries

It is known that a periodic structure in the form of Benard cells [1] is formed in a horizontal layer of a viscous, incompressible, below-heated liquid. Rayleigh described in [2] the physical nature of the convection onset in such layers. He obtained analytical expressions for perturbed velocity and temperature in the Cartesian coordinate system. On the basis of this theory, it was possible to explain the threshold nature of the convective instability development, when the convection occurs only at a certain temperature difference. The obtained solutions describe the occurrence of convective rolls in a horizontal liquid layer, on the vertical common boundaries of which the velocity was directed periodically up / down and vice versa. However, these solutions did not describe the experimental fact of the availability of polygonal structures, the number of angles of which varied from four to seven, but with a predominance of six [1]. Therefore, to explain the appearance of hexagonal convective cells, geometric transformations of the found solutions were used. The description of cells with a different number of angles also means involving geometric manipulations. And if we continue the work and try to describe the entire set of polygonal convective cells, then this task turns out to be practically impossible.

In contrast to the method of geometric transformations described above, the energy principle of the formation of Benard cells was proposed in the work [3]. The principle is based on the fact that cells in the nucleation phase are few in number and have a cylindrical form [3]. As the temperature of the lower boundary of the layer increases, their number increases. Ideally, all cells are tightly packed in a liquid layer, and create a polygonal (hexagonal or other) structure, i.e. Benard cells.

As we see, initially the main element of Benard cells is an elementary cylindrical convective cell, whose perturbed parameters under free boundary conditions are described in the work [3]. At a uniform rotation of the liquid in the cell relative to the vertical axis, new possibilities of controlling the thermal convection described in [1 - 3] emerge. The control parameters under the new conditions will be Coriolis and centrifugal forces $[4,5]$.

In this work the onset of convection in a uniformly rotating and below-heated cylindrical tank with a viscous, incompressible liquid with free boundaries was investigated.

\section{THE INITIAL EQUATIONS OF CONVECTION IN A ROTATING VISCOUS, INCOMPRESSIBLE LIQUID OF A CYLINDRICAL FORM WITH FREE BOUNDARIES}

Let us consider a cylindrical volume of radius $R_{0}$ filled with a viscous, incompressible liquid, the lower and upper boundaries of which coincide with the planes $z=0$ and $z=h$. The liquid rotates uniformly as a whole with an angular velocity $\vec{\Omega}=\Omega \cdot \vec{e}_{z}$, where $\vec{e}_{z}$ - the unit vector directed along the vertical, which coincides in direction with the 
axis $z$ and is in the gravitational field, the direction of acceleration of which is $\vec{g}=-g \cdot \vec{e}_{z}$ opposite to the direction of the axis $z$. In Fig. 1 vector $\vec{g}$ - gravitational acceleration, $\vec{r}$ - radial coordinate.

The temperature distribution inside the cylinder $T_{0}(z)$ is set so, that the temperature of the lower boundary is higher than the temperature of the upper one: $T_{0}(0)=T_{0,2}, T_{0}(h)=T_{0,1},\left(T_{0,2}>T_{0,1}\right)$. We suppose, that in equilibrium the temperature distribution is described by a linear function in the coordinate $z$ :

$$
\vec{\nabla} T_{0}(z)=-\frac{\Theta}{h} \vec{e}_{z}
$$

were, $\Theta=T_{0,2}-T_{0,1}$ - the temperature difference between lower and upper plains.

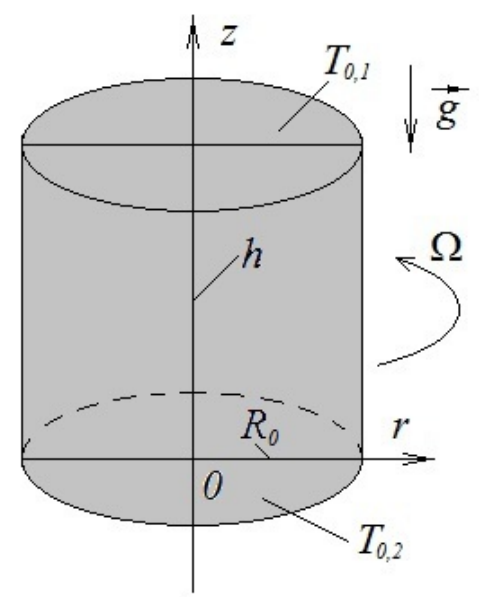

Fig. 1. Schematic representation of a cylindrical volume with a viscous incompressible liquid rotating at an angular velocity $\Omega$ in a gravitational field $\vec{g}$.

Let us write the equations describing convection in a cylindrical volume heated from below and rotating as a whole. These equations consist of the Navier - Stokes equation, with regard to inertial forces in a rotating coordinate system - Coriolis and centrifugal [4], the heat conduction equation and the continuity equation:

$$
\begin{gathered}
\frac{\partial \overrightarrow{\mathrm{v}}}{\partial t}+(\overrightarrow{\mathrm{v}} \vec{\nabla}) \overrightarrow{\mathrm{v}}=-\frac{1}{\rho} \vec{\nabla} p+v \Delta \overrightarrow{\mathrm{v}}+\vec{g}-2 \vec{\Omega} \times \overrightarrow{\mathrm{v}}-\vec{\Omega} \times(\vec{\Omega} \times \vec{r}), \\
\frac{\partial T}{\partial t}+(\overrightarrow{\mathrm{v}} \vec{\nabla}) T=\Delta T \\
\operatorname{div}(\overrightarrow{\mathrm{v}})=0
\end{gathered}
$$

where $\overrightarrow{\mathrm{v}}$ - small perturbations of the liquid velocity in a rotating coordinate system, $\vec{r}$ - radius-vector of the liquid element, $\rho, p, T$ density, pressure and temperature of the liquid, $\vec{\nabla}$ - gradient operator, $\Delta$ - Laplace operator.

From system (1-3) it is possible to obtain equations that describe the spatial-temporal dynamics of small perturbations of pressure $\tilde{p}$ and temperature $\tilde{T}$ with respect to their equilibrium values $p_{0}(r, z)$ and $T_{0}(z)=T_{0,2}-\frac{\Theta}{h} z:$

$$
p=p_{0}+\tilde{p}, T=T_{0}(z)+\tilde{T} .
$$

Small values of pressure and temperature perturbations meet the requirement: $|\tilde{f}|<<\left|f_{0}\right|$.

When analyzing the Navier - Stokes equation we assume that Boussinesq's assumptions regarding the being determind influence of the temperature compressibility of a liquid are met, i.e. we assume $\rho=\rho_{0}(1-\beta \tilde{T})$ [4], where $\beta$ - the coefficient of a liquid temperature compressibility.

We assume, that the velocity perturbations are small, which allows us to neglect the quadratic in velocity summands in (1). Taking into account the assumptions made, and after substitution (4) into equation (1) we have:

$$
(1-\beta \tilde{T}) \frac{\partial \overrightarrow{\mathrm{v}}}{\partial t}=-\frac{1}{\rho_{0}} \vec{\nabla}\left(p_{0}+\tilde{p}\right)+v \Delta \overrightarrow{\mathrm{v}}-(1-\beta \tilde{T}) g \overrightarrow{e_{z}}-2 \vec{\Omega} \times \overrightarrow{\mathrm{v}}-(1-\beta \tilde{T}) \vec{\Omega} \times(\vec{\Omega} \times \vec{r}) .
$$


We suppose the diameter of the cylindrical tank is small: $D<<g \Omega^{-2}$. This condition allows neglecting the centrifugal convective force, as a result of which the last summand in (5) can be neglected [4].

Let us eliminate the unperturbed summands in the equation (5), setting:

$$
\vec{\nabla} p_{0}=-\rho_{0} g \vec{e}_{z}
$$

The remaining summands give the force balance equation for perturbed values:

$$
\frac{\partial \overrightarrow{\mathrm{v}}}{\partial t}=-\frac{1}{\rho_{0}} \vec{\nabla} \tilde{p}+v \Delta \overrightarrow{\mathrm{v}}+\beta \tilde{T} g \vec{e}_{z}-2 \vec{\Omega} \times \overrightarrow{\mathrm{v}} .
$$

In units of layer thickness $h$, time $\tau=h^{2} v^{-1}$ and temperature $\Theta$ the equation (7) is converted to a dimensionless form:

$$
\frac{\partial \overrightarrow{\mathrm{v}}^{\prime}}{\partial t^{\prime}}=-\vec{\nabla} \tilde{p}^{\prime}+\Delta \overrightarrow{\mathrm{v}}^{\prime}+R \tilde{T}^{\prime} \vec{e}_{z}-E^{-1} \vec{e}_{z} \times \overrightarrow{\mathrm{v}}^{\prime}
$$

where the "prime mark" denotes the corresponding dimensionless value, $R=g \beta h^{3} \Theta /(v \chi)$ - the Rayleigh number, $v$ and $\chi$ - the coefficients of liquid kinematic viscosity and thermometric conductivity, correspondingly, $E=v /\left(2 \Omega h^{2}\right)-$ the Ekman number, which is very small in most experiments with rotating liquid [6].

In further calculations to simplify writing process the "prime mark" notation is omitted.

Equation (8) should be supplemented by the equation of heat conduction (2), which, taking into account the linear dependence of temperature on height, takes the dimensionless form:

$$
P \frac{\partial \tilde{T}}{\partial t}-\overrightarrow{\mathrm{v}} \vec{e}_{z}=\Delta \tilde{T}
$$

where $P=v / \chi-$ the Prandtl number.

The continuity equation (3) in dimensionless variables has the same form. For a rotating viscous, incompressible liquid of a cylindrical form we will assume that the boundary conditions are free $[2,4,5]$. These conditions mean that vertical projections of the velocity perturbations are equal to zero at the boundaries of the liquid:

$$
\left.\mathrm{V}_{z}\right|_{\substack{z=0, z=1}}=0
$$

and tangential stresses:

$$
\sigma_{r z}=\left.\rho_{0} v\left(\frac{\partial \mathrm{v}_{r}}{\partial z}+\frac{\partial \mathrm{v}_{z}}{\partial r}\right)\right|_{\substack{z=0, z=1}}=0 .
$$

The boundary conditions (11) taking into account the continuity equation (3) can be transformed to the form:

$$
\left.\frac{\partial^{2} \mathrm{v}_{z}}{\partial z^{2}}\right|_{\substack{z=0, z=1}}=0
$$

We assume that the temperature at horizontal boundaries of the cylinder is fixed. It follows that the temperature perturbations at the boundaries $z=0, z=1$ are equal to zero:

$$
\left.\tilde{T}\right|_{\substack{z=0, z=1}}=0 \text {. }
$$

To the boundary conditions (10), (12), (13), we should add the condition for the perturbed velocity at the external boundary: $\mathrm{v}_{r}(r, z, t)=\mathrm{v}_{\varphi}(r, z, t)=0$ at $r=R_{0}$.

As an initial condition we assume, that at the time point $t=0$ all the perturbations are either missing:

$$
\overrightarrow{\mathrm{v}}, \tilde{T},\left.\tilde{p}\right|_{t=0}=0
$$

or specified as:

$$
\overrightarrow{\mathrm{v}}, \tilde{T},\left.\tilde{p}\right|_{t=0}=\overrightarrow{\mathrm{v}}(\vec{r}, 0), \tilde{T}(\vec{r}, 0), \tilde{p}(\vec{r}, 0) .
$$

Thus, the problem of studying the stability of a rotating, heated from below, viscous, incompressible liquid of a cylindrical form with free boundaries is reduced to solving the eigen value problem for the system of equations (3), (8), (9) with boundary conditions (10), (12), (13) [4] and with initial conditions (14), (15). 


\section{SOLUTIONS OF THE ORIGINAL SYSTEM OF EQUATIONS}

We write equations (3), (8), (9) in a cylindrical coordinate system $r, \varphi, z$. We assume the perturbations are axisymmetric, i.e. such that the perturbations do not depend on the angular coordinate $\varphi$. This means that all the perturbed values meet the condition $\partial \ldots / \partial \varphi=0$. Rotation of the cylindrical volume of a liquid is a flow with an equilibrium azimuthal velocity $V_{\varphi}(r)=\Omega \cdot r[7,8]$, which is obtained from the Couette flow, if we set the radius and angular velocity of rotation of the inner cylinder to zero. Based on this we write the projections of the velocity vector in the cylinder: $\overrightarrow{\mathrm{v}}=\left(\mathrm{v}_{r}, V_{\varphi}(r)+\mathrm{v}_{\varphi}, \mathrm{v}_{z}\right)$.

The equations for the perturbed velocity projections follow from (8):

$$
\begin{gathered}
\frac{\partial \mathrm{v}_{r}}{\partial t}=-\frac{\partial}{\partial r} \tilde{p}+\Delta \mathrm{v}_{r}-\frac{\mathrm{v}_{r}}{r^{2}}+E^{-1} \mathrm{v}_{\varphi}, \\
\frac{\partial \mathrm{v}_{\varphi}}{\partial t}=\Delta \mathrm{v}_{\varphi}-\frac{\mathrm{v}_{\varphi}}{r^{2}}-E^{-1} \mathrm{v}_{r}, \\
\frac{\partial \mathrm{v}_{z}}{\partial t}=-\frac{\partial}{\partial z} \tilde{p}+\Delta \mathrm{v}_{z}+R \tilde{T},
\end{gathered}
$$

where $\Delta=\frac{1}{r} \frac{\partial}{\partial r}\left(r \frac{\partial}{\partial r}\right)+\frac{\partial^{2}}{\partial z^{2}}$.

In cylindrical coordinates the continuity equation (3) is converted to the form:

$$
\frac{1}{r} \frac{\partial}{\partial r}\left(r \mathrm{v}_{r}\right)+\frac{\partial}{\partial z} \mathrm{v}_{z}=0
$$

Equations (16) (19) should be supplemented by the equation of heat balance (9).

We will seek solutions of the original task in the form:

$$
\begin{gathered}
\mathrm{v}_{r}(r, z, t)=-A \cdot \exp (-\lambda t) \cdot n \pi k_{r}^{-1} \cos (n \pi z) J_{1}\left(k_{r} r\right), \\
\mathrm{v}_{\varphi}(r, z, t)=D \cdot \exp (-\lambda t) \cdot \cos (n \pi z) J_{1}\left(k_{r} r\right), \\
\mathrm{v}_{z}(r, z, t)=A \cdot \exp (-\lambda t) \cdot \sin (n \pi z) J_{0}\left(k_{r} r\right), \\
\tilde{p}(r, z, t)=C \cdot \exp (-\lambda t) \cdot \cos (n \pi z) J_{0}\left(k_{r} r\right) . \\
\tilde{T}(r, z, t)=B \cdot \exp (-\lambda t) \cdot \sin (n \pi z) J_{0}\left(k_{r} r\right)=B(t) \cdot \sin (n \pi z) J_{0}\left(k_{r} r\right),
\end{gathered}
$$

where $\lambda$ - eigen values characterizing attenuation $(\lambda>0)$, increase $(\lambda<0)$ or stationary state $(\lambda=0)$ of perturbations (18); $A, B, C, D=\frac{A n \pi}{k_{r} E\left(k_{r}^{2}+(n \pi)^{2}-\lambda\right)}$ - perturbation amplitudes; $J_{0}(x), J_{1}(x)$ - Bessel functions of the first kind of zero and first order of the argument $x$ respectively; $k_{r}$ - radial wave number characterizing the dependence of the perturbations on the transverse coordinate $r, n=1,2,3 \ldots$ - the mode number.

It is easy to see, that the boundary conditions on the external boundary are automatically satisfied, if we set $k_{r}=\sigma_{1, i} / R_{0}$, where $\sigma_{1, i}-i$ - th zero of Bessel functions of the first kind of the first order $\left(J_{1}\left(\sigma_{1, i}\right)=0\right), i=1,2,3, \ldots$.

From (20) a), c), and e) it follows that the spatial distribution of perturbations of horizontal and vertical velocities and temperature are similar to those implemented for a layer of heated from below, viscous, incompressible liquid without rotation in a cylindrical coordinate system [3].

\section{THE STABILITY ANALYSIS OF A ROTATING, VISCOUS, INCOMPRESSIBLE, HEATED FROM BELOW LIQUID OF A CYLINDRICAL FORM}

Substitution of solutions (20) into equations (9), (16) (18) gives a cubic characteristic equation for determining eigen values $\lambda$ :

$$
\lambda^{3}+a \lambda^{2}+b \lambda+c=0
$$


where, $a=-k_{\perp}^{2} \frac{(2 P+1)}{P}, b=k_{\perp}^{4} \frac{(P+2)}{P}+\frac{P(n \pi)^{2} T e-k_{r}^{2} R}{k_{\perp}^{2} P}, c=\frac{k_{r}^{2} R-k_{\perp}^{6}-(n \pi)^{2} T e}{P}, \quad k_{\perp}^{2}=k_{r}^{2}+(n \pi)^{2}$, $T e=E^{-2}=4 \Omega^{2} h^{4} / v^{2}$ - Taylor number.

Let us consider the solutions of the characteristic equation (21), which describe a stable rotation of a viscous, incompressible and heated from below liquid of a cylindrical form.

We determine the condition of a monotone instability of a rotating, viscous, incompressible and below-heated liquid of a cylindrical form from (21), similarly to [5].

$$
k_{r}^{2} R_{c}=\left(\left(k_{\perp}^{2}\right)^{3}+(n \pi)^{2} T e\right)
$$

where $R_{c}$ - critical Rayleigh number of monotone instability.

It should be noted, that the expression (22) goes into the expression obtained in the Cartesian coordinate system by Rayleigh, if we replace $k_{r}^{2}$ by $k^{2}=k_{x}^{2}+k_{y}^{2}[4,5]$.

The condition of monotone instability (22) in graphic form is shown in Fig. 2. Here the dependence of the lines of the logarithm levels of the critical Rayleigh number $\ln \left(R_{c}\right)$ upon the wave number $k_{r}$ and the Taylor number Te is presented.

The level lines show, that the wave number $k_{r, \mathrm{~m}}$ (the abscissa of the maximum of the level line) corresponding to the minimum critical Rayleigh number increases with increasing Taylor number, starting from the value of $k_{r, \mathrm{~m}}=\pi / \sqrt{2} \approx 2.221$ [5]. In this case, the critical Rayleigh number increases also from value $R_{c}^{*}=27(n \pi)^{4} / 4 \approx 657.11$ that corresponds to the case of no rotation, i.e. $\Omega=0$.

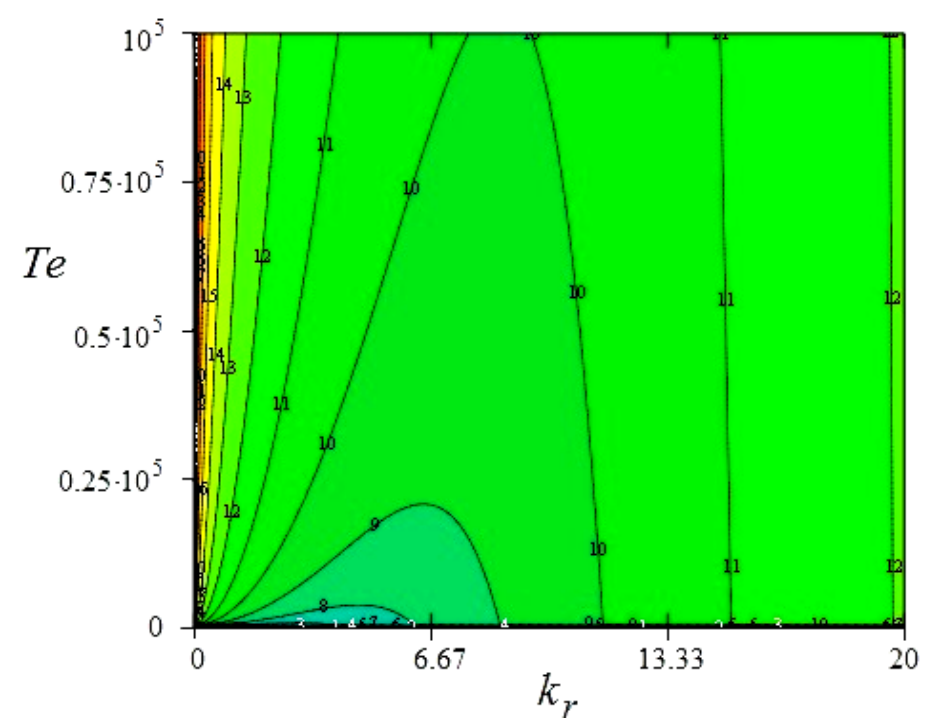

Fig. 2. Lines of the logarithm level of the critical Rayleigh number $\ln \left(R_{c}\right)$ versus the wave number $k_{r}$ and the Taylor number $T e$.

Let us define the conditions for the equation fulfillment (22).

We rewrite the equation (22) relatively the unknown $k_{\perp}^{2}$, and get an incomplete cubic equation:

$$
\left(k_{\perp}^{2}\right)^{3}+p k_{\perp}^{2}+q=0
$$

where $p=-R_{c} ; q=(n \pi)^{2}\left(T e+R_{c}\right)$.

Since $k_{\perp}^{2}=k_{r}^{2}+(n \pi)^{2}>0$, then we will look only for real positive solutions of the equation (23).

It is known that the type of solutions (23) depends on the sign of the discriminant $Q$ :

$$
Q=\left(\frac{p}{3}\right)^{3}+\left(\frac{q}{2}\right)^{2}=\left(\frac{(n \pi)^{2} R_{c}^{*}}{2}\right)^{2}\left[\frac{T e}{R_{c}^{*}}+\frac{R_{c}}{R_{c}^{*}}\left(\sqrt{\frac{R_{c}}{R_{c}^{*}}}+1\right)\right]\left[\frac{T e}{R_{c}^{*}}-\frac{R_{c}}{R_{c}^{*}}\left(\sqrt{\frac{R_{c}}{R_{c}^{*}}}-1\right)\right]
$$


The discriminant $Q$ is positive for $T e / R_{c}^{*}>R_{c} / R_{c}^{*}\left(\sqrt{R_{c} / R_{c}^{*}}-1\right)>0$. The equation (23) in this case has one negative real and two complex conjugate roots. Therefore, by the requirement of $k_{\perp}^{2}>0$ the solutions (23) are not considered for the case $Q>0$.

The discriminant $Q$ is equal to zero for $T e / R_{c}^{*}=R_{c} / R_{c}^{*}\left(\sqrt{R_{c} / R_{c}^{*}}-1\right)$. The equation (23) has one negative and two coincident positive roots. The negative root is equal to $\left(k_{\perp}^{2}\right)_{1}=-2 \sqrt[3]{\left((n \pi)^{2}\left(T e+R_{c}\right)\right) / 2}$ and positive roots $\left(k_{\perp}^{2}\right)_{2,3}=-\frac{1}{2} \sqrt[3]{-\frac{q}{2}+\sqrt{Q}}-\frac{1}{2} \sqrt[3]{-\frac{q}{2}-\sqrt{Q}}=\sqrt[3]{q / 2}=\sqrt[3]{\left((n \pi)^{2}\left(T e+R_{c}\right)\right) / 2}$. Therefore, $k_{\perp}^{2} \quad$ can only take the value $k_{\perp}^{2}=\sqrt[3]{\left((n \pi)^{2}\left(T e+R_{c}\right)\right) / 2}$.

The discriminant $Q$ is negative for Taylor numbers $0<T e / R_{c}^{*}<R_{c} / R_{c}^{*}\left(\sqrt{R_{c} / R_{c}^{*}}-1\right)$. This condition is true for Rayleigh numbers $R_{c} / R_{c}^{*}>1$. Within these ranges of variation of the Rayleigh and Taylor numbers the equation (23) has three different real roots. From them, by virtue of the requirement, we select positive root within the whole range of variation $T e$ and $R_{c}$ :

$$
\left(k_{\perp}^{2}\right)_{3}=-\left(\frac{(n \pi)^{2} R_{c}^{*}}{2}\right)^{\frac{1}{3}}\left[\sqrt[3]{i \sqrt{\left[X^{3}-(Y+X)^{2}\right]}-(Y+X)}\right] \frac{1+i \sqrt{3}}{2}+\text { c.c. }
$$

where $\mathrm{Y}=T e / R_{c}^{*}, \quad X=R_{c} / R_{c}^{*}$, c.c. - denotes a complex conjugate value.

The lines of the logarithm level of the radial wave number $\ln \left(k_{r}\right)$ versus the Rayleigh number $\left(1 \leq R_{c} / R_{c}^{*} \leq 10\right)$ and the Taylor number $(0 \leq T e \leq 100)$ for the case $n=1$ are presented in Fig. 3.

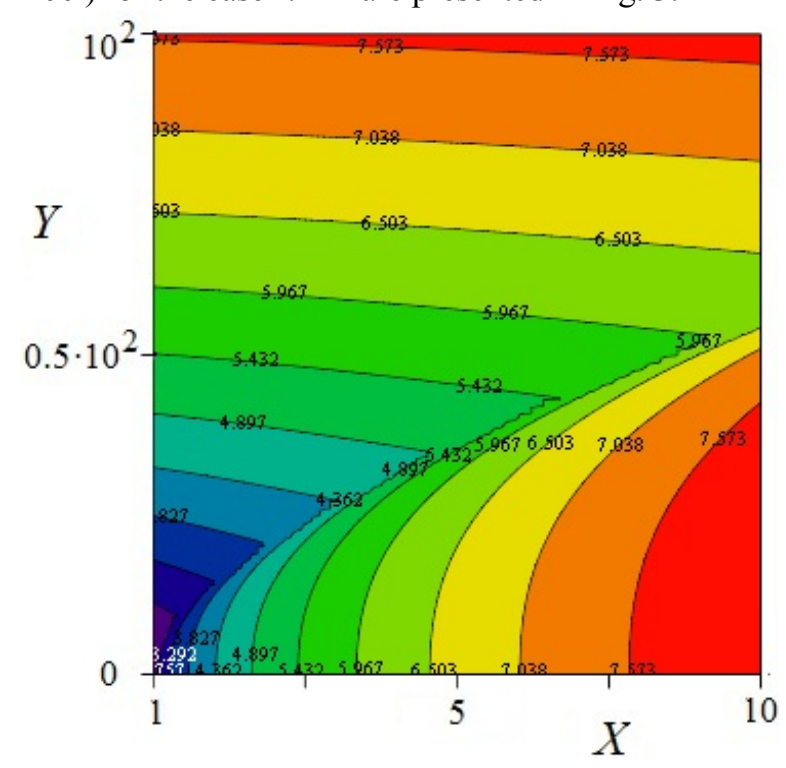

Fig. 3. Lines of the logarithm level of the radial wave number $\ln \left(k_{r}\right)$ versus

the Rayleigh number $X=R_{c} / R_{c}^{*}$ and the Taylor number $Y=T e / R_{c}^{*}$

According to the level lines for the radial wave number, $\left(k_{r}\right)_{\min }$ differs in exponent from that given in [5] by a factor of two

Thus, from the Fig. 3 it is seen that the minimum radial wave number (the inflection points of level lines) increases nonlinearly with increasing the Taylor number and the Rayleigh number.

At large Taylor numbers $Y>>1$ the minimum critical Rayleigh number varies according to the law $\left(R_{c}\right)_{\min } \sim\left(R_{c}^{*}\right)^{1 / 3} T e^{2 / 3}=\left(27 \pi^{4} / 4\right)^{1 / 3} \mathrm{Te}^{2 / 3}=3\left(\pi^{2} / 2\right)^{2 / 3} \mathrm{Te}^{2 / 3} \quad[5,9]$ and the corresponding radial wave number $-\left(k_{r}\right)_{\min } \sim\left(\pi^{2} / 2\right)^{1 / 3} T e^{1 / 3}$ (Fig. 2).

It should be noted that the expression of monotone instability (22) is observed for the values of radial wave numbers: 


$$
k_{\perp}^{2}=\sqrt[3]{\left((n \pi)^{2}\left(T e+R_{c}\right)\right) / 2}, k_{\perp}^{2}=-\left(\frac{(n \pi)^{2} R_{c}^{*}}{2}\right)^{\frac{1}{3}} \sqrt[3]{i \sqrt{\left[X^{3}-(Y+X)^{2}\right]}-(Y+X)} \frac{1+i \sqrt{3}}{2}+\text { c.c. }
$$

To analyze the stability of perturbations of the boundary-value problem we turn to expressions (21), (22).

Further, when describing the stability of perturbations in a medium, we will consider only the perturbed temperature, noting that the transition to other perturbed quantities is carried out in accordance with expressions (20), a) - e).

The fulfillment of the monotone instability condition (22) gives the following eigen values of the problem:

$$
\lambda_{1}^{c}=0, \lambda_{2,3}^{c}=k_{\perp}^{2} \frac{(2 P+1)}{2 P} \pm \sqrt{k_{\perp}^{4} \frac{(1-4 P)}{4 P^{2}}-\frac{P(n \pi)^{2} T e-k_{r}^{2} R_{c}}{k_{\perp}^{2} P}} .
$$

The perturbed temperature (20), e) depends on time as a general solution of the characteristic equation (21), consisting of the sum of partial perturbations:

$$
B(t)=\sum_{m=1}^{3} C_{m}^{\prime} \exp \left(-\lambda_{m} t\right)
$$

where $C_{m}^{\prime}$ - arbitrary constants determined by initial conditions, $m=1 ; 2 ; 3$.

For the case of the development of monotonous instability, the eigen value $\lambda_{1}=\lambda_{1}^{c}$ equal to zero corresponds to the time-invariant amplitude of the partial perturbation and the eigen values $\lambda_{2,3}=\lambda_{2,3}^{c}$ describe the temporal dynamics of the partial perturbations depended on the radicand value.

Below, we consider the solution (21) for the case with lack of external temperature effect (the lower boundary of the layer is not heated), as well as for the case when this temperature effect occurs.

\section{THE STABILITY ANALYSIS OF A ROTATING LIQUID CYLINDRICAL VOLUME WITHOUT HEATING FROM BELOW}

Let us determine the characteristic numbers of the equation (21) without heating the liquid from below. Despite the fact that there is no heating of the liquid, the Rayleigh number is not equal to zero, but it is determined by the temperature difference between the lower $T_{2, f l}$ and upper $T_{1, f l}$ boundaries at the fluctuation level: $\Theta_{f l}=T_{2, f l}-T_{1, f l}$.

The temperature fluctuation value of the upper boundary of the liquid cylindrical volume with radius $R_{V}$ and thickness of several molecular layers $h_{V}$ is determined by a number of water molecules in it and the average temperature of the medium $T^{*}$ [10]: $T_{1, f l} \sim N^{-\frac{1}{2}} T^{*}$, where $N$ is the number of particles in the volume $V \sim \pi R_{V}^{2} h_{V}$. For water the fluctuation level of temperatures is sufficiently small and is of the order of $\Theta_{f l} \approx 10^{-8} \div 10^{-7} \mathrm{C}$.

Therefore, if the liquid is not heated from below, we assume that the Rayleigh number is equal to $R=R_{f l}$, where $R_{f l}=g \beta h^{3} \Theta_{f l} /(v \chi)$ - the Rayleigh number for the fluctuation temperature difference between the lower and upper boundaries of the tank. Here it should also be noted that the temperature unit in (8) is no longer $\Theta$ as well $\Theta_{f l}$. However, this value is clearly not included in the characteristic equation (21), and thus does not affect its solutions.

At the above fluctuation level of temperature difference, the Taylor number is a fairly large value: $T e>R_{f l}, k_{\perp}^{2}>>1$

In this case, the discriminant of the equation (21) takes the value $Q_{0} \approx\left(\pi^{2} T e / 3 k_{\perp}^{2}\right)^{3}+\left(\pi^{2} T e(P-1) / 3 P\right)^{2}>0$, that corresponds to one real root and two complex conjugate roots $\lambda_{2,3}=k_{\perp}^{2} \pm i\left(\frac{\pi^{2} T e}{k_{\perp}^{2}}\right)^{\frac{1}{2}}$

Substituting the roots of the characteristic equation in (28) and assuming $C_{2}^{\prime \prime}=-\left(C_{2}^{\prime}+C_{3}^{\prime}\right), C_{3}^{\prime \prime}=i\left(C_{3}^{\prime}-C_{2}^{\prime}\right)$ we get:

$$
B(t)=C_{1}^{\prime} \exp \left(-\frac{\alpha_{1}}{P} t\right)-\left(C_{2}^{\prime \prime} \cos \left(\alpha_{2} t\right)-C_{3}^{\prime \prime} \sin \left(\alpha_{2} t\right)\right) \exp \left(-\alpha_{1} t\right)
$$

where $\alpha_{1}=k_{\perp}^{2}, \alpha_{2}=\left(\pi^{2} T e / k_{\perp}^{2}\right)^{\frac{1}{2}}, \alpha_{2} \gg \alpha_{1}$. 
If we set in (29), for example, $C_{2}^{\prime \prime}=C_{1}^{\prime}$ and, $C_{3}^{\prime \prime}=0$ then the amplitude $B(t)$ will have the form:

$$
B(t)=C_{1}^{\prime} \exp \left(-\frac{\alpha_{1}}{P} t\right)\left(1-\exp \left(-\left(\frac{P-1}{P}\right) \alpha_{1} t\right) \cos \left(\alpha_{2} t\right)\right)
$$

Further everywhere, without loss of generality, we can set $C_{1}^{\prime}=1$ in (30).

The temperature difference between the horizontal boundaries of the liquid is fixed and equal to zero

As noted above, in case with no heating from below the temperature difference between the horizontal boundaries of the liquid is not equal to zero, but it is determined by the fluctuation level $\Theta_{f l}=T_{2, f l}-T_{1, f l}$.

From (30) it follows, that the amplitude of the perturbed temperature as a result of action of viscous forces increases from zero at $t=0$ to a maximum value at $t=t_{\max }$. After reaching a maximum it decreases to zero, oscillating with exponentially decreasing amplitude of oscillations. The law of decreasing the average amplitude value $B(t)$ is determined by the expression (30) averaged over the period of fast oscillations.

The temperature variation rate of the liquid (30) at the initial time (zero time) is equal to $\left.\frac{d B_{T}}{d t}\right|_{t=0}=\Theta_{f l} \cdot\left(\frac{P-1}{P}\right) \alpha_{1}$, where $B_{T}$ - the liquid temperature in ${ }^{\circ} \mathrm{C}$.

The temperature dependence upon the time for different values $\alpha_{2}$ is presented in Fig. 4 .

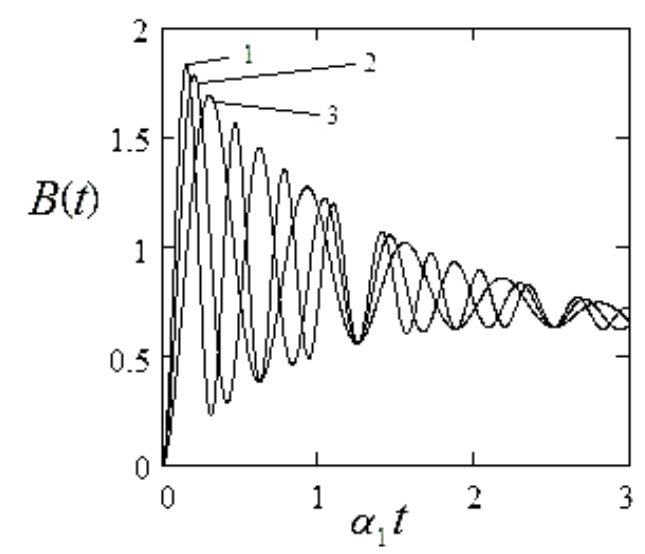

Fig. 4. Temperature $B(t)$ versus time without water heating from below for different values $\alpha_{2}: 1-\alpha_{2}=10 \cdot \alpha_{1} ; 2-\alpha_{2}=15 \cdot \alpha_{1} ; 3-\alpha_{2}=20 \cdot \alpha_{1}$.

From Fig. 4 it follows that with increasing $\alpha_{2}$ and, consequently, the Taylor number, the amplitude of the first temperature maximum increases and the time of the maximum reaching decreases.

Thus, in rotating liquid cylindrical volume with free horizontal boundaries at a temperature difference between the lower and upper boundaries at the fluctuation level, increasing the perturbed temperature from zero is observed. Then it reaches a maximum $B(t) \approx 1.5, \ldots, 2.0=\kappa$, and after it again decreases to zero with exponentially decreasing amplitude of oscillations. In the final state at large times the water will rotate as a whole without perturbation of velocity, pressure and temperature.

However, it should be noted, that the value of the first maximum of the liquid temperature exceeds the fluctuation level by a factor of $\kappa \approx 1.5, \ldots, 2.0$. This indicates that the liquid is being heated within the time interval $0 \leq t \leq t_{\text {max }}$.

\section{The temperature difference between the horizontal boundaries of the liquid is not fixed and not supported from the outside}

If the temperature difference between the horizontal boundaries of the liquid cylindrical volume $\Theta$ is specified at the fluctuation level and is not supported from the outside, then the system can be considered as isolated. In such a system according to (30) the temperature $B(t)$ will increase from zero to the maximum value $\kappa$ within the time interval $0 \leq t \leq t_{\max }$ (refer to Fig. 4)

According to (30) a point in time $t=t_{\max }$, when the temperature should decrease with time increasing, comes in the system. However, this cannot be realized, since the entropy of an isolated system $S_{f l}(t)$ is a non-decreasing function of time [11], i.e. the condition $d S_{f l} / d t \geq 0$ should be met. 
Based on the principle of entropy increasing we will describe the dynamics of temperature variation in the system within the time interval $t>t_{\max }$.

The law of variation of the system entropy can be written using (30) in the form:

$$
\frac{d S_{f l}}{d t}=\frac{\Theta_{f l}}{\kappa T_{2, f l} T_{1, f l}}\left(\kappa-\exp \left(-\frac{\alpha_{1}}{P} t\right)\left(1-\exp \left(-\left(\frac{P-1}{P}\right) \alpha_{1} t\right) \cos \left(\alpha_{2} t\right)\right)\right) \frac{d S_{1, f l}}{d t}>0
$$

where, $S_{f l}=S_{2, f l}+S_{1, f l}=$ const - the sum of entropies of microvolumes on the lower and upper boundaries of the liquid, $d S_{1, f l} / d t>0$ - the entropy of the upper boundary increased with time.

From (31) it follows that the entropy increases for the time interval $0 \leq t<t_{\max }$. At times $t>t_{\max }$ the inequation (31) is violated, i.e. the entropy decreases. Therefore, the system has one way out: at the point of time $t=t_{\max }$ it passes from the first stage of instability to the second. At this stage of instability the cylindrical volume of a liquid is described by the original system of equations (9), (16) - (19), but with the temperature difference at the boundaries of the volume increased by a factor $\kappa$ compared with the first stage: $\Theta_{f l} \rightarrow \kappa \Theta_{f l}$. Increasing the temperature difference at the liquid boundaries by a factor $\kappa$ leads to the same increase of the Rayleigh number: $R_{f l} \rightarrow \kappa R_{f l}$.

The overall increase of the liquid temperature at the second stage will be equal to $(1+\kappa)$. Increasing the Rayleigh number does not violate the applicability of the characteristic equation (21) and the expression (30), since the condition $T e \gg \curvearrowright R_{f l}$ is still met.

At the third stage, the process of increasing the temperature will repeat, and the maximum temperature will now be equal to $\kappa^{2}$. The overall increase of the temperature will be equal to $\left(1+\kappa+\kappa^{2}\right)$.

With multiple repeating of temperature rise stages, the liquid temperature will increase in increasing geometric progression to the value $\sum_{i=1}^{n} \kappa^{i-1}$, where $n>>1$ - the number of stages of the temperature rise.

However, with a certain number of rise stages $n=N>>1$, the Rayleigh number $R=R_{f l} \sum_{i=1}^{N} \kappa^{i-1}$ may increase to a value $R=R_{c}$. In this case the characteristic equation (21) will have another eigen values and, consequently, another expression for the temperature $B(t)^{1}$. At that, the liquid temperature will increase, but its final value should not exceed the temperature of the phase transition. Otherwise, the original system of equations is not applicable.

As an example of heating a uniformly rotating cylindrical volume of a viscous, incompressible liquid can be used the heating of water in the Ranque - Hilsch vortex tubes $[12,13]$.

For a pure water with an initial fluctuation level of the temperature difference $\Theta_{f l} \approx 10^{-7}{ }^{\circ} \mathrm{C}[10]$ and $\kappa \approx 1.8$, heating to a temperature difference of the order of $(8-9) \cdot 10^{-20} \mathrm{C}$ (temperature difference at which the Rayleigh number increases to a value $R=R_{c}$ ) corresponds to the number of temperature rise stages $n \approx 23$.

Further increase of the difference in the water temperature from (8-9) $10^{-2} \mathrm{C}$ to a given temperature is a continuation of the previous multistage rise and will be described in the next Section (Stationary temperature perturbations at large Rayleigh numbers $\left(R=R_{c}\right)$ ).

As follows from the above analysis, heating of the rotating volume of water in Ranque - Hilsch tubes is due to the action of viscous forces. The spatial distribution of the vertical and horizontal velocity of water coincides with a similar distribution in the Rayleigh problem on convection in a layer of a viscous, incompressible liquid heated from below. Therefore, the problem of occurrence of a temperature gradient in a rotating volume of water, as well as the problem of heating water in Ranque -Hilsch tubes should be considered as the inverse Rayleigh problem.

Rayleigh's inverse problem involves searching the temperature difference between the boundaries of a viscous, incompressible liquid of a cylindrical form according to a given distribution of its vertical and horizontal velocities.

Analysis of the stability of a rotating cylindrical volume of liquid when heated from below

The expression for the perturbed temperature (30) will change if the rotating cylindrical volume of the liquid is heated from below with a certain rate. To show this, let us set a dependence of the perturbed temperature amplitude upon the time at heating in the form:

$$
B_{h}(t)=B(t) \alpha_{T} \exp \left(\lambda_{T} t\right)
$$

\footnotetext{
${ }^{1}$ The solution of the characteristic equation (21) and the expression for the perturbed temperature for large Rayleigh numbers are given in Section 5 .
} 
where $\alpha_{T}, \lambda_{T}$ - constants determining the parameters of water heating.

Such a representation is similar to introduction to the characteristic equation (22) a number with a shift $\lambda-\lambda_{T}$ instead of an eigen value $\lambda$, where the shift value $\lambda_{T}$ is selected so that to reduce the free term $c$ to zero.

From (32) it follows, that there is no heating for the parameter values $\alpha_{T}=1$ and $\lambda_{T}=0$.

If we set $\lambda_{T}=\alpha_{1} / P$, we will get the expression for the temperature of the rotating liquid with heating:

$$
B_{h}(t)=C_{1}^{\prime \prime}\left(1-\exp \left(-\left(\frac{P-1}{P}\right) \alpha_{1} t\right) \cos \left(\alpha_{2} t\right)\right)
$$

where $B_{h}(t)=B_{T, h} / \Theta_{e x}$ is measured in units $\Theta_{e x}=T_{2, e x}-T_{1, e x}, B_{T, h}$ - liquid temperature - in ${ }^{\circ} \mathrm{C}, T_{2, e x}, T_{1, e x}$ temperatures of the lower and upper boundaries of the liquid layer, respectively.

We will assume $C_{1}^{\prime \prime}=1$ in (33), as before.

The dependence of the perturbed temperature amplitude upon the time (33) for different values $\alpha_{2}$ is presented in Fig.4.

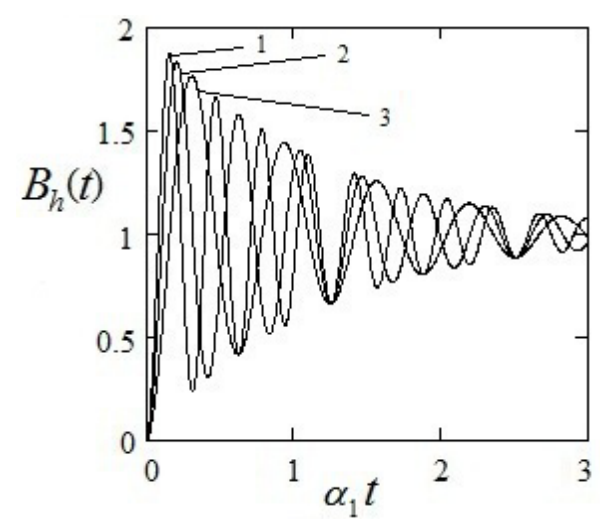

Fig. 5. Temperature $B_{h}(t)$ versus time at heating from below for different values $\alpha_{2}: 1-\alpha_{2}=10 \cdot \alpha_{1} ; 2-\alpha_{2}=15 \cdot \alpha_{1} ; 3-\alpha_{2}=20 \cdot \alpha_{1}$.

From Fig. 5 it follows, that the liquid temperature increases from zero with time at $t=0$, reaches the first maximum $B_{h}(t) \approx \kappa$ and oscillating with an exponentially decreasing amplitude tends to unity.

From this we can conclude, that in experiments with heating a rotating cylindrical volume of liquid, the value $\Theta_{e x}$ determines the final temperature of the liquid heating, as well as the initial rate of temperature variation, i.e. $\left.\frac{d B_{T, h}}{d t}\right|_{t=0}=\Theta_{e x} \cdot\left(\frac{P-1}{P}\right) \alpha_{1}$. It follows that the rate of variation in the temperature of a heated liquid is greater than that of a non-heated one.

STATIONARY TEMPERATURE PERTURBATIONS AT LARGE RAYLEIGH NUMBERS $\left(R=R_{c}\right)$

As follows from the previous presentation, the temperature difference between the horizontal boundaries of the rotating cylindrical volume of a liquid increases. This leads to an increase in the Rayleigh number, which may possess eventually a value $R=R_{c}$. In this case, the characteristic equation (22) has solutions in the form of stationary perturbations, which differ from solutions (33).

Let us consider these stationary perturbations.

The eigen values of the characteristic equation at $R=R_{c}$ are as follows:

$$
\lambda_{1}=0 ; \lambda_{2,3}=k_{\perp}^{2} \frac{(2 P+1)}{2 P} \pm i \omega
$$

where $n=1, R_{w}=\frac{k_{\perp}^{6}(2 P-1)^{2}}{4 k_{r}^{2}(P-1) P}, \omega^{2}=\frac{(P-1)}{P} \frac{k_{r}^{2}}{k_{\perp}^{2}}\left(R_{c}-R_{w}\right)$.

We will set the dependence of temperature on time in (20), e) for eigen values (34) in the form $D(t)=B \exp (-\lambda t)$. Then the overall solution can be represented as: 


$$
D(t)=\sum_{m=1}^{3} D_{m} \exp \left(-\lambda_{m} t\right)=D_{1}-\left(D_{2} \cos (\omega t)-D_{3} \sin (\omega t)\right) \exp (-\delta t)
$$

where $D_{m}$ - arbitrary constants determined by initial conditions.

From (35) it follows, that in a stationary state the general solution for the liquid perturbed temperature consists of the sum of three particular solutions. One summand with an eigen value $\lambda_{1}=0$ is a constant number. The other two summands with eigen values $\lambda_{2,3}$ describe either exponentially damped temperature variation with a damping decrement $\quad \operatorname{Re}\left(\lambda_{2,3}\right)=\alpha_{1}^{R_{c}>R_{w}}=k_{\perp}^{2} \frac{(2 P+1)}{2 P} \quad$ and $\quad$ oscillation $\quad$ frequency $\operatorname{Im}\left(\lambda_{2,3}\right)=\alpha_{2}^{R_{c}>R_{w}}= \pm \sqrt{\frac{(P-1)}{P} \frac{k_{r}^{2}}{k_{\perp}^{2}}\left(R_{c}-R_{w}\right)}$ at $R_{c}>R_{w}$, or damped variation without oscillations with decrements $\operatorname{Re}\left(\lambda_{2,3}\right)=\alpha_{1,2}^{R_{c}<R_{w}}=k_{\perp}^{2} \frac{(2 P+1)}{2 P} \pm \sqrt{\frac{k_{r}^{2}}{k_{\perp}^{2}} \frac{(P-1)}{P}\left(R_{w}-R_{c}\right)}$ at $R_{c}<R_{w}$. Moreover, in the latter case $\alpha_{1}^{R_{c}<R_{w}}>\delta_{2}^{R_{c}<R_{w}}>0$.

We use the expressions (33), (35) to describe the experimental data on the stability of a rotating cylindrical volume of water heated from below $[5,9]$.

In some experiments (let's designate them as experiments I) the water was placed in glass cylinders with an outer diameter of $29.4 \mathrm{~cm}$. An electric heating element was attached to the horizontal bottom of the cylinder, which provided controllable temperature variation. Heating was carried out at a low rate (heater power - $1 \mathrm{~W}$ ), medium rate (heater power $-3 \mathrm{~W}$ ) and high rate (heater power - $10 \mathrm{~W}$ ). The cylinder with water rotated around its axis using special tools. The layer of water with a depth of $3 \mathrm{~cm}$ and the rotation velocity of $10 \mathrm{rpm}$ was studied in the experiments.

For experiments I) in (34), the relation $R_{c}>R_{w}$ is satisfied and, thus, the instability with the parameters $\alpha_{1,2}^{R_{c}>R_{w}}$ is realized.

In other experiments (experiments II) [4, 9] in water layers of $18 \mathrm{~cm}$ depth at a temperature difference of lower and upper boundaries $-0.7^{\circ} \mathrm{C}$ and a rotation velocity of $5 \mathrm{rpm}$ we have found by visual observations using a rotoscope, that for a heating rate of more definite value in a cylindrical volume of water rotating as a whole the convective cells with a diameter of $4.6 \mathrm{~cm}$ arose. The motion inside the cells becomes visible as a result of dispersing a small amount of aluminum powder over the surface of the water.

We will analyze the described experiments on the basis of the performed analytical calculations below.

\section{Stationary temperature perturbation at a low rate of liquid heating}

At a low rate of heating the bottom of the tank, the process of water heating will take place in two stages. These stages, due to the low rate of liquid heating and the low level of saturation temperature, will not go into one another, but overlap, i.e. to the first stage of temperature variation, valid within the entire time interval, one should add the second stage of its variation, valid after the temperature is established of the order of $(8-9) \cdot 10^{-2 \circ} \mathrm{C}$ (when the equality $R=R_{c}$ is satisfied).

At the first stage the water temperature increases as a result of multi-stage rise, reaches values of the order of $8-9 \cdot 10^{-2 \circ} \mathrm{C}$ and the Rayleigh number increases to a value $R=R_{c}$. This stage of the multistage temperature rise will be approximated by the expression:

$$
B_{h}(t)=A_{s}\left(1-\exp \left(-B_{s} t\right)\right) \theta\left(t_{t r}-t\right),
$$

where $A_{s}, B_{s}$ - constants describing the first stage of water heating, $t_{t r}$ - the time of transition of water temperature rise from the first stage to the second.

At the second stage, when $R \simeq R_{c}$, the temperature variation is described by the sum of two temperatures, where the first temperature from this sum $B_{h}^{\prime}(t)$ is set by the sum of the summands of the solution (36) with arbitrary coefficients

$$
B_{h}^{\prime}(t)=A_{s}^{\prime}-D_{s}^{\prime} \exp \left(-B_{s} t\right)
$$

and the second $D(t)$ is the sum of particular solutions of the characteristic equation at $R=R_{c}$ :

$$
\begin{aligned}
& D(t)=\theta\left(t-t_{t r}\right)\left\{D_{1}-\left(D_{2} \cos \left(\alpha_{2}^{R_{c}>R_{w}} t\right)-D_{3} \sin \left(\alpha_{2}^{R_{c}>R_{w}} t\right)\right) \exp \left(-\alpha_{1}^{R_{c}>R_{w}} t\right)\right\}= \\
& =\theta\left(t-t_{t r}\right)\left(A_{e}+B_{e} \cos \left(C_{e}\left(t-t_{e}\right)\right) \exp \left(-D_{e}\left(t-t_{e}\right)\right)\right)
\end{aligned}
$$


where $A_{s}^{\prime}, D_{s}^{\prime}, A_{e}, B_{e}, C_{e}, D_{e}, t_{e}$ - constants describing the second stage of water heating.

After summing up the solutions (37), (38) we obtain an expression for water temperature variation at the second stage of instability:

$$
D_{\Sigma}(t)=\left(A_{s}^{\prime}+A_{e}\right) \theta\left(t-t_{t r}\right)\left(1-\frac{D_{s}^{\prime} e^{-B_{s} t_{e}}}{A_{s}^{\prime}+A_{e}}\left(1-\frac{B_{e}}{D_{s}} e^{B_{s} t_{e}} \cos \left(C_{e}\left(t-t_{e}\right)\right)\right) e^{-B_{s}\left(t-t_{e}\right)}\right),
$$

where $\theta(x)$ - Heaviside unit function.

Constants in (39) can be determined by combining the theoretical dependencies (36), (39) with experimental data $[4,9]$.

Graphs of temperature versus time for the rotating cylindrical volume of water heated from below, obtained experimentally, and calculated by formulas (36), (39) are presented in Fig. 6. The experimental dependence of temperature upon time (solid line) was obtained as a result of digitization and graphic transformation to the Cartesian coordinate system. The beginning of the obtained experimental curve was brought into coincidence with the beginning of the Cartesian coordinate system.

As a result of approximation of formulas (36), (39) with experimental data the following values of the constants were obtained: $A_{s}=36.4, B_{s}=0.055, A_{s}^{\prime}=D_{s}^{\prime}=8.86, A_{e}=0, B_{e}=1.92, C_{e}=0.5, D_{e}=B_{s}=0.08, t_{e}=-1, t_{t r}=15.8$.

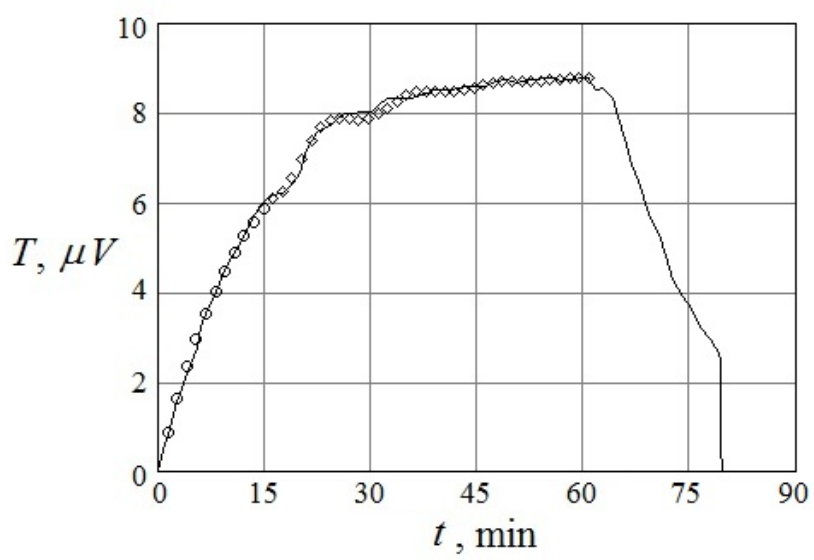

Fig. 6. Temperature versus time of a rotating cylindrical volume of water with a low

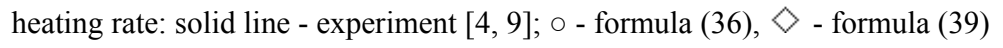

In Fig. 6 the water heating rate at the initial time is determined by the quantity: $\left.\frac{d B_{h}}{d t}\right|_{t=0}=0.676$, it is a fairly small quantity.

From Fig. 6 it follows, that the experimental data and theoretical dependences are quantitatively consistent. The data show, that in a rotating cylindrical volume of water with a low heating rate, a monotonic rise in temperature to a certain level and its stabilization at a slightly higher level are observed. Lack of convective vortices in the experiment indicates that temperature stabilization in a cylindrical volume of water occurs, apparently, due to mechanical heat and mass transfer, which occurs as a result of the liquid rotation.

The radial and vertical spatial distribution of the velocity of mechanical heat and mass transfer of a rotating liquid, as follows from (20), is determined by the same expressions as for convective heat and mass transfer in the below heated water layer with free boundaries [3].

\section{Stationary temperature perturbation at high heating rate}

At the tank heating rate of more than a definite value the process of water heating can be divided also into two stages. However, the second stage of temperature variation, due to the high rate of water heating and rapid establishment of the equality $R=R_{c}$, will be described only by the sum of particular solutions of the characteristic equation.

Thus, at the first stage in the time interval $0 \leq t<t_{\max }$ the water will be heated to the value $(1.5 \div 2) T_{e x}$ according to the law (36).

At the second stage, when $t \geq t_{\max }$, the temperature variation is described by the expression:

$$
\begin{aligned}
& D^{\prime}(t)=\theta\left(t-t_{t r}\right)\left\{D_{1}^{\prime}-\left(D_{2}^{\prime} \cos \left(\alpha_{2}^{R_{c}>R_{w}} t\right)-D_{3}^{\prime} \sin \left(\alpha_{2}^{R_{c}>R_{w}} t\right)\right) \exp \left(-\alpha_{1}^{R_{c}>R_{w}} t\right)\right\}= \\
& =\theta\left(t-t_{t r}\right)\left(A_{e}^{\prime}+B_{e}^{\prime} \sin \left(C_{e}^{\prime}\left(t-t_{e}^{\prime}\right)\right) \exp \left(-D_{e}^{\prime}\left(t-t_{e}^{\prime}\right)\right)\right) .
\end{aligned}
$$


The constants in (36), (40) can be determined by combining theoretical dependences with experimental data.

Graphs of temperature versus time of a rotating cylindrical volume of water heated from below, obtained experimentally and calculated by formulas (36), (40) are presented in Fig. 7. The experimental temperature dependence on time was taken from [4, 9], digitized, and graphically transformed to the Cartesian coordinate system. The beginning of the experimental curve thus obtained was brought into coincidence with the beginning of the Cartesian coordinate system.

As a result of approximation of the experimental data using formulas (36), (40) the following values of the constants were obtained: $A_{s}=36.4, B_{s}=0.055, A_{e}^{\prime}=15.45, B_{e}^{\prime}=27.245, C_{e}^{\prime}=0.557, D_{e}^{\prime}=0.197, \quad t_{e}^{\prime}=8.3411, t_{t r}=15.57$.

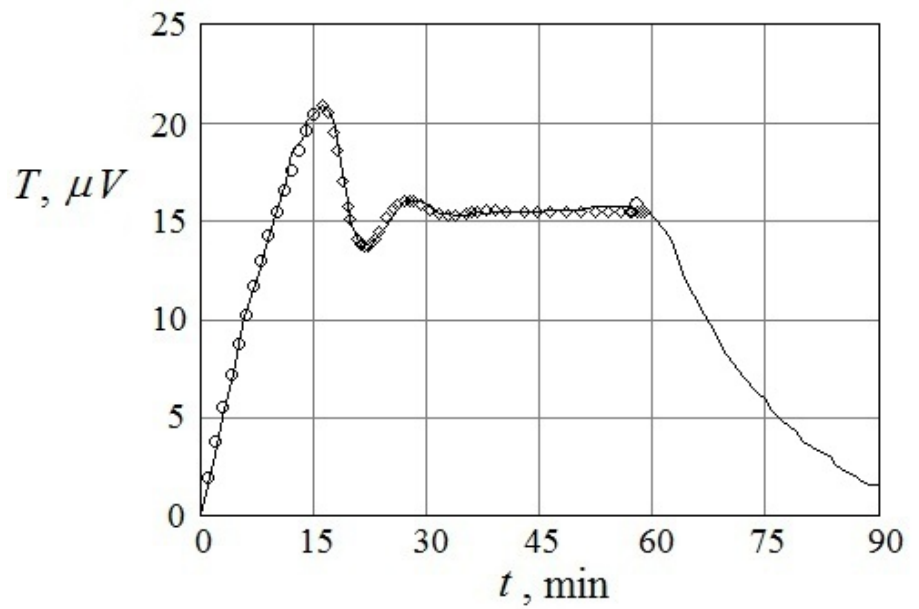

Fig. 7. Temperature versus time of a rotating cylindrical volume of water heated from below with a high heating rate: solid line - experiment $[4,9] ; \circ$ - formula (36), $>$ - formula (40).

In Fig. 7 the water heating rate at the initial time is determined by the value: $\left.\frac{d B_{h}}{d t}\right|_{t=0}=2.0$. It can be seen that in the case under consideration the water heating rate at the initial time is higher than the heating rate in the experiment described above.

From Fig. 7 it follows, that at the first stage within the time interval $0 \leq t<t_{\max }$ the temperature increases according to the exponential law (36) to a certain level. Then, at $t \approx t_{\max }$ the first stage goes into the second, where the perturbed temperature variation is described by the expression (40). At that, the perturbed temperature experiences oscillations damped in time with respect to temperature $T \approx 15.45$.

It should be noted, that in Fig. 6, 7 and below, the part of the experimental curve, not marked with markers, describes the water temperature variation after the heater is turned off.

Let us consider another experiment in which the water heating rate was higher than the heating rate used in the experiment in Fig. 7.

Fig. 8 shows experimentally obtained and calculated by formulas (36), (40) graphs of dependence of the disturbed temperature upon the time of a cylindrical volume of water heated from below at rate exceeding the heating rate in the experiment in Fig. 7.

As before, the experimental dependence of temperature difference on time [4, 9] is digitized, and graphically transformed to the Cartesian coordinate system. The beginning of the experimental curve thus obtained was brought into coincidence with the beginning of the Cartesian coordinate system.

As a result of approximation of the experimental data using formulas (36), (40) the following values of the constants were obtained: $A_{s}=52.5, B_{s}=0.055, A_{e}^{\prime}=14.817, B_{e}^{\prime}=3.592, C_{e}^{\prime}=0.772, D_{e}^{\prime}=0.2, t_{e}^{\prime}=11.451, t_{t r}=8.44$.

In Fig. 8 the water heating rate at the initial time is higher than the heating rate in two previous experiments $\left.\frac{d B_{h}}{d t}\right|_{t=0}=2.9$.

From Fig. 8 it follows that increasing the water heating rate compared with the data in Fig. 7 changes the temporal dynamics of the perturbed temperature: the first stage of heating exists for a shorter period of time, and the damped vibrations at the second stage have a shorter period and larger amplitude of oscillations. As to the rest, the amplitude dynamics of the perturbed temperature in Fig. 8 corresponds to the dynamics in Fig. 7: the amplitude of the first maximum and the saturation level are almost the same.

The discrepancy between the experimental data and the theoretical curve in Fig. 8 at $t>t_{\max }$ is, apparently, due to the fact that with a high heating rate it is necessary to take into account the contribution of nonlinear summands in the initial equations (9), (16) - (19). 


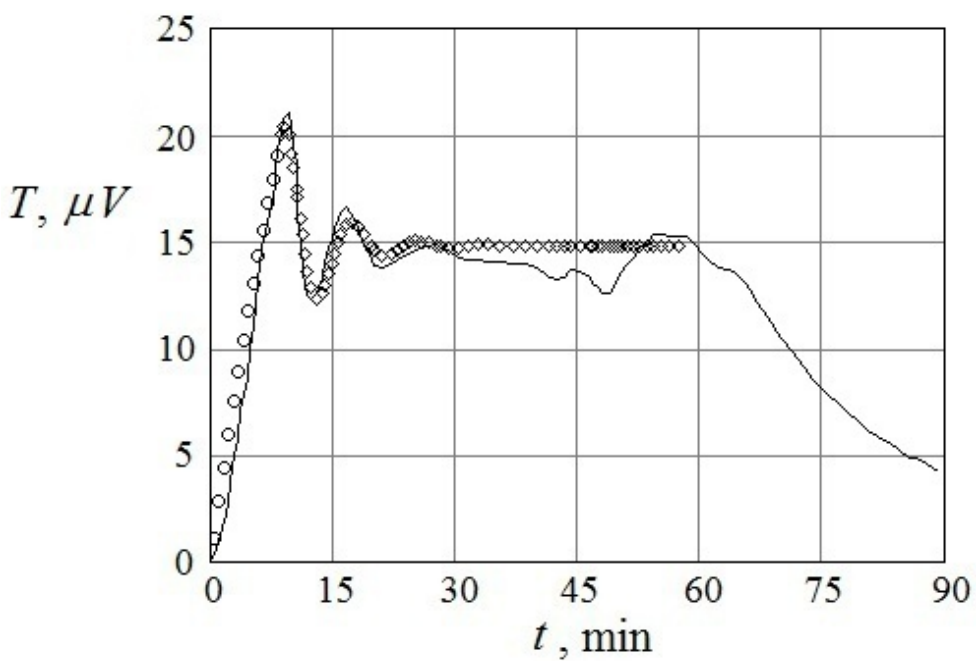

Fig. 8. Temperature versus time of a rotating cylindrical volume of water with a high heating rate: solid line - experiment [4, 9]; ○ - curve (36), $\diamond$ - curve (40).

\section{CONCLUSION}

In this work, in neglect of the centrifugal convective force, the equations of heat and mass transfer in a rotating, viscous, incompressible liquid of a cylindrical form with free boundaries are analyzed. Solutions of the linearized original system of equations in cylindrical geometry are obtained that satisfy the boundary conditions of the problem. The spatial distributions of the projections of the perturbed velocity and the perturbed temperature of the liquid are determined with the accuracy to constants.

It is shown, that the spatial distribution of horizontal and vertical velocities and the temperature of a rotating, viscous, incompressible liquid of a cylindrical form with free boundaries are similar to those implemented for a layer of a viscous, incompressible liquid heated from below without rotation, which correspond to solutions of the Rayleigh problem in the cylindrical coordinate system.

The analysis of stability of a rotating, viscous, incompressible liquid of a cylindrical form heated from below was carried out. A stability condition for the rotating, viscous, incompressible liquid of a cylindrical form heated from below in the cylindrical coordinate system was obtained. For the case of its stable rotation the graphs of dependence of the logarithm of the critical Rayleigh number $\ln \left(R_{c}\right)$ on the wave number $k_{r}$ and the Taylor number $T e$, as well as the logarithm of the radial wave number $\ln \left(k_{r}\right)$ on the Rayleigh number $X=R_{c} / R_{c}^{*}$ and the Taylor number $Y=T e / R_{c}^{*}$ were plotted. The obtained dependences, except for the minimum radial wave number $\left(k_{r}\right)_{\min } \sim\left(\pi^{2} / 2\right)^{1 / 3} T e^{1 / 3}$, fully match the previous studies by other authors.

The stability analysis of a rotating cylindrical volume of a liquid without heating from below was carried out. It has been shown that at a fixed, zero temperature difference between the horizontal boundaries of the cylindrical tank of a liquid, an increase in its temperature is observed starting from zero. Then it reaches a maximum value of the $\operatorname{order} \kappa=1.5, \ldots, 2.0$, and after, oscillating with exponentially decreasing amplitude of oscillations, again decreases to zero. In the final state at large times the liquid will rotate as a whole without perturbations of velocity, pressure and temperature.

If the temperature difference between the horizontal boundaries of the cylindrical volume of the liquid $\Theta$ is set at a fluctuation level and is not supported from the outside, then the system can be considered as isolated. In this case, according to the law of entropy increasing in isolated systems, the liquid will successively go through only the stages of temperature rise with the rise coefficient at each stage of the order $\kappa$ so, that its temperature eventually will increase in increasing geometric progression up to the value $\sum_{i=1}^{n} \kappa^{i-1}$, where $n>>1$ - the number of stages of the temperature rise. However, at a certain number of rise stages $n=N$, the Rayleigh number $R=R_{f f} \sum_{i=1}^{N} \kappa^{i-1}$ may increase to a value $R=R_{c}$. In this case, the characteristic equation will have another eigen values and, consequently, another expression for increasing the liquid temperature. The water temperature will increase, but its final value should not exceed the phase transition temperature, since in this case the original system of equations is not applicable.

Based on performed calculations an example of heating a rotating cylindrical volume of water without heating from below is considered. This example shows that the problem of the occurrence of a temperature gradient in the volume of water, as well as its heating in Ranque-Hilsch tubes, should be considered as an inverse Rayleigh problem. In 
the Rayleigh inverse problem it is required to find the temperature difference between the horizontal boundaries of a viscous, incompressible liquid of a cylindrical form according to a given distribution of its horizontal and vertical velocities.

The stability analysis of a rotating cylindrical volume of a liquid at heating from below has shown, that over time the temperature difference of the liquid increases from zero at $t=0$, reaches the first maximum value of the order $\kappa$ and tends to unity oscillating with exponentially decreasing oscillation amplitude. In experiments with heating the rotating cylindrical volume of a liquid, the value of the temperature difference set from outside determines the final heating temperature of the liquid, as well as the initial rate of its variation. It is shown that the rate of temperature variation of a heated liquid is greater than that of a similar one without heating.

Stationary temperature perturbations are considered for different rates of water heating.

In all cases it was proposed to consider two stages of the development of stationary perturbations.

At the first stage the water, as a result of a multistage heating at a rate set from outside, acquires a temperature at which the Rayleigh number is small, but increases from the value $R<<R_{c}$ to $R \approx R_{c}$.

At the second stage of heating, when $R=R_{c}$, the eigen values of the characteristic equation and the type of particular solutions, of which the general solution for a temperature consists, change. The temperature of the system is described either by a superposition of general solutions for the first and second stages of the temperature rise (at a low heating rate), or only by a general solution for the case $R=R_{c}$ (at a high heating rate).

Comparison of theory and experimental data for heating water shows a qualitative and quantitative agreement.

\section{ORCID IDs}

Oksana L. Andreeva https://orcid.org/0000-0001-9757-8519, -Leonid A. Bulavin https://orcid.org/0000-0002-8063-6441

(D)Viktor I. Tkachenko https://orcid.org/0000-0002-1108-5842

\section{REFERENCES}

[1] H. Bernard, Revue generale des Sciences, pures et appliquées, 11, 1261-1271 and 1309-1328 (1900), retrieved from: https://gallica.bnf.fr/ark:/12148/bpt6k17075r? rk =21459;2.

[2] J.W. Strutt (Lord Rayleigh), Phil. Mag. 32, 529-546 (1916), https://doi.org/10.1080/14786441608635602.

[3] L.S. Bozbei, B.V. Borts, A.O. Kostikov and V.I. Tkachenko, East Eur. J. Phys. 1(4), 49-56 2014, retrieved from: https://periodicals.karazin.ua/eejp/article/view/1442.

[4] S. Chandrasekhar, Hydrodynamic and hydromagnetic stability, (University Press, Oxford, 1970), pp. 657.

[5] G.Z. Gershuni and E.M. Zhukhovitskiy, Конвективная устойчивость несжимаемой жидкости [Convective stability of an incompressible fluid], (Nauka, Moscow, 1972), pp. 393. (in Russian)

[6] Kh.P. Grinspen, Теория вращающихся жидкостей [Theory of Rotating Fluids], (Gidrometeoizdat, Leningrad, 1975), pp. 321. (in Russian)

[7] L.D. Landau and E.M. Lifshits, Tеоретическая физика, T.6, Гидродинамика [Theoretical Physics, Vol.6, Hydrodynamics], (Nauka, Moxcow, 1986), pp. 736. (in Russian)

[8] E.L. Koschmieder, Bénard Cells and Taylor Vortices: monograph on mechanics, (University Press, Cambridge, 1993), pp. 350.

[9] Y. Nakagawa and P. Frenzen, Tellus, 7, 1-21 (1955), https://doi.org/10.1111/j.2153-3490.1955.tb01137.x.

[10] N.A. Smirnova, Методы статистической термодинамики в физической химии [Methods of statistical thermodynamics in physical chemistry], (Vysshaya shkola, Moscow, 1982), pp. 455. (in Russian)

[11] L.D. Landau and E.M. Lifshits, Tеоретическая физика, T.5, Статистическая физика [Theoretical Physics Vol.5, Statistical Physics], (Nauka, Moscow, 1976), pp. 584. (in Russian)

[12] A.P. Merkulov, Вихревой эффект и его применение в технике [Vortex effect and its application in technology], (Mashinostroeniye, Moscow, 1969), pp. 183. (in Russian)

[13] A.D. Suslov, S.V. Ivanov., A.V. Murashkin and Yu.V. Chizhikov, Buxревые annapambl [Vortex devices], (Mashinostroeniye, Moscow, 1985), pp. 256. (in Russian)

\section{СТІЙКІСТЬ ГОРИЗОНТАЛЬНОГО ЦИЛІНДРИЧНОГО ШАРУ В'ЯЗКОЇ, НЕСТИСЛИВОЇ РІДИНИ з ВІЛЬНИМИ МЕЖАМИ, ЩО ОБЕРТАЄТЬСЯ ТА ПІДІГРІВАЕТЬСЯ ЗНИЗУ}

О.Л. Андрєєва ${ }^{1,2}$, Л.А. Булавін ${ }^{3}$, В.І. Ткаченко ${ }^{1,2}$

${ }^{1}$ Національний науковий центр «Харківський фізико-технічний інститут» вул. Академічна, 1, 61108, Харків, Украӥна

${ }^{2}$ Харківський національний університет імені В.Н. Каразіна майдан Свободи, 4, 61022, Харків, Украӥна

${ }^{3}$ Київський національний університет імені Тараса Шевченка вул. Володимирська, 60, 01033, Київ, Україна

Теоретично досліджено стійкість циліндричного горизонтального шару в'язкої, нестисливої рідини з вільними межами, що обертається і підігрівається знизу. У нехтуванні відцентровими силами записані рівняння руху, теплопровідності і нестисливості рідини, з яких в лінійному наближенні отримано відоме дисперсійне рівняння. Розглянуто стійкість обертового циліндричного об'єму рідини у відсутність підігріву знизу за умови, що різниця температур горизонтальних границь рідини фіксована, і дорівнює нулю. Показано, що у відсутність підігріву знизу і якщо різниця температур горизонтальних кордонів рідини, що обертається, не фіксована, і не підтримується ззовні, то збурена температура рідини буде збільшуватися, але ії кінцеве значення не перевищуватиме температуру фазового переходу. Отриманий результат використаний для пояснення нагріву води у вихрових трубках Ранка-Хілша. Зроблено висновок про те, що нагрів води в 
трубках типу Ранка-Хілша слід розглядати як зворотну задачу Релея, в якій за відомим розподілом швидкостей всередині об'єму рідини можна визначити градієнт температури, що виникає. Наведено аналіз стійкості обертового циліндричного об'єму рідини при підігріві знизу. Показано, що в експериментах величина різниці температур на кордонах циліндра, задається, а також початкова швидкість ії зміни визначає кінцеву температуру нагрівання рідини. Порівняння запропонованої теорії та експериментальних даних для нагріву води показує їх гарну якісну і кількісну відповідність.

КЛЮЧОВІ СЛОВА: теорія, стійкість, в'язкий, нестисливий, рідина, горизонтальний циліндричний шар, обертається, нагрівається, вільні границі

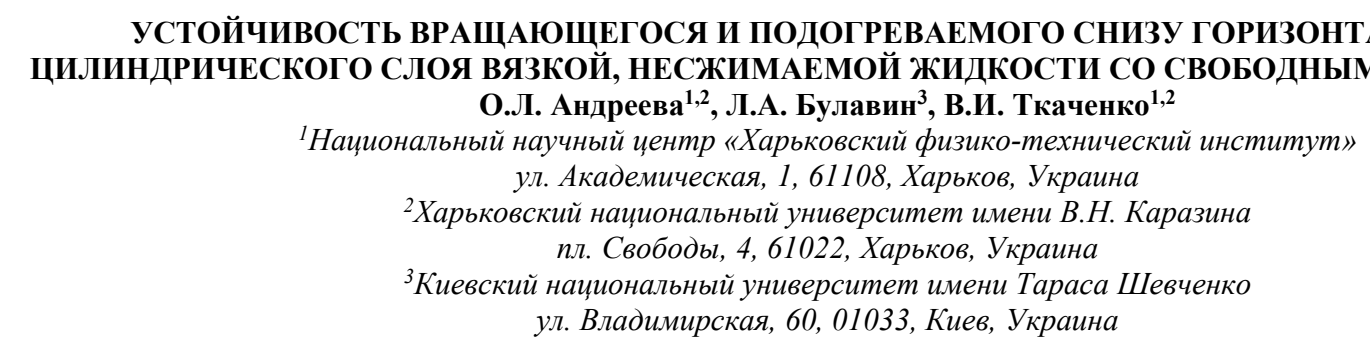

Теоретически исследована устойчивость вращающегося и подогреваемого снизу горизонтального цилиндрического слоя вязкой, несжимаемой жидкости со свободными границами. В пренебрежении центробежными силами записаны уравнения движения, теплопроводности и несжимаемости жидкости, из которых в линейном приближении получено известное дисперсионное уравнение. Рассмотрена устойчивость вращающегося цилиндрического объема жидкости в отсутствие подогрева снизу при условии, что разность температур горизонтальных границ жидкости фиксирована, и равна нулю. Показано, что в отсутствие подогрева снизу и, если разность температур горизонтальных границ вращающейся жидкости не фиксирована, и не поддерживается извне, то возмущенная температура жидкости будет увеличиваться, но ее конечное значение не превышает температуру фазового перехода. Полученный результат использован для объяснения нагрева воды в вихревых трубках Ранка-Хилша. Сделан вывод о том, что нагрев воды в трубках типа Ранка-Хилша следует рассматривать как обратную задачу Рэлея, в которой по известному распределению скоростей внутри объема можно определить возникающий градиент температуры. Приведен анализ устойчивости вращающегося цилиндрического объема жидкости при подогреве снизу. Показано, что в экспериментах величина задаваемой разности температур на границах цилиндра, а также начальная скорость ее изменения определяет конечную температуру нагрева жидкости. Сравнение предложенной теории и экспериментальных данных для нагрева воды показывает их хорошее качественное и количественное соответствие.

КЛЮЧЕВЫЕ СЛОВА: теория, устойчивость, вязкий, несжимаемый, жидкость, горизонтальный цилиндрический слой, вращается, нагревается, свободные границы 